\title{
Proteomic analysis identifies nuclear protein effectors in PKC- $\delta$ signaling under high glucose-induced apoptosis in human umbilical vein endothelial cells
}

\author{
FANG SUN, BO ZHOU, XUEBO LIN and LIAN DUAN \\ Department of Endocrinology, The First Affiliated Hospital of Chongqing Medical University, Chongqing 400016, P.R. China
}

Received February 22, 2011; Accepted July 4, 2011

DOI: $10.3892 / \mathrm{mmr} .2011 .531$

\begin{abstract}
Although experimental animal and clinical trials have suggested that additional mechanisms other than protein kinase $\mathrm{C}$ (PKC)- $\beta$ activation are involved in the vascular pathology of diabetic complications, current knowledge on the role of PKC- $\delta$ is incomplete and inconclusive. Human umbilical vein endothelial cells (HUVECs) were cultured in both high and normal glucose conditions and infected with recombinant adenovirus to overexpress PKC- $\delta$. PKC- $\delta$ expression was also down-regulated using the PKC- $\delta$ inhibitor, rottlerin. Using flow cytometric analysis, we showed that PKC- $\delta$ is activated and translocates to the nucleus under high glucose conditions. Augmented cell apoptosis and cell cycle arrest were observed in a PKC- $\delta$-dependent manner in the HUVECs. Furthermore, proteomic analyses identified 51 high glucose-induced and PKC- $\delta$-associated proteins, and subsequent matrix-assisted laser desorption/ionization time of flight mass spectrometry analysis uncovered a total of 37 unique proteins. The majority of identified proteins were previously unknown targets of PKC- $\delta$ signaling and were involved in the regulation of the cell cycle and apoptosis, tumor suppression, transcription, stress and signal transduction within the nucleus. Our data show that PKC- $\delta$ is an important mediator of cell apoptosis and cell cycle arrest in HUVECs under high glucose stress.
\end{abstract}

\section{Introduction}

Disturbances in endothelial cell homeostasis are known to be primary cellular events in the development of diabetic

Correspondence to: Dr Bo Zhou, Department of Endocrinology, The First Affiliated Hospital of Chongqing Medical University, Chongqing 400016, P.R. China

E-mail: zhoubo915@126.com

Abbreviations: ROS, reactive oxygen species; FOXO1, forkhead box O1A; PDGF, platelet-derived growth factor; NO, nitric oxide; eNOS, endothelial nitric oxide synthase; MALDI-MS, matrixassisted laser desorption/ionization mass spectrometry; SGK1, serine/threonine protein kinase; GRP 78, 78-kDa glucose-regulated protein; CDKN2A, cyclin-dependent kinase inhibitor $2 \mathrm{~A}$

Key words: proteomics, protein kinase C- $\delta$, diabetic complication, apoptosis, nuclear translocation vascular complications $(1,2)$. Although previous studies have demonstrated that high ambient glucose levels can increase cell proliferation, disturb the cell cycle, increase DNA damage and accelerate cell death (3-6), the precise molecular mechanism by which diabetes leads to endothelial cell injury remains to be fully eludicated. Recently, a large body of evidence has strongly implicated the activation of protein kinase $\mathrm{C}$ (PKC) in the pathogenesis of diabetic vascular disease (7-9). However, the global characterization of the signaling mechanism of the $\mathrm{PKC}$ isoforms involved is still unknown.

The PKC- $\beta$ and PKC- $\delta$ isoforms appear to be preferentially activated both in vitro and in the vasculature of diabetic animals $(10,11)$. Although experimental animal and clinical trials have suggested that additional mechanisms other than PKC- $\beta$ activation are involved in the vascular pathology of diabetic retinopathy (12), the current knowledge on the role of PKC- $\delta$ is incomplete and inconclusive. Studies have demonstrated that the chronic exposure of cells (such as endothelial cells, mesangial cells or smooth muscle cells) to high glucose increases the levels of diacylglycerol-activated PKC- $\delta$ (13). In addition, activated $\mathrm{PKC}-\delta$ appears to redistribute to the plasma membrane in mesangial cells (14), to the perinuclear cytosol in coronary endothelial cells (10) and into the nucleus in L6 skeletal muscle cells (15). Moreover, recent findings implicate a role of PKC- $\delta$ in promoting apoptosis. In pericytes, exposure to high glucose promotes apoptosis through two pathways involving reactive oxygen species (ROS) induction of $N F-\kappa B$ activity and deactivation of the platelet-derived growth factor (PDGF) receptor $\beta$ (12). In ovine fetal pulmonary artery endothelial cells, apoptosis occurs through the ERK or Akt pathways by regulating nitric oxide (NO) generation and endothelial nitric oxide synthase (eNOS) expression (16). In beta-cells exposed to fatty acids, inhibition of forkhead box O1A (FOXO1) activation promotes apoptosis (17). The many pathways in which PKC- $\delta$ acts, suggest that PKC- $\delta$ affects diverse initial or terminal events in the apoptotic pathway.

However, all previous approaches have only focused on one known molecule or signaling pathway. As cell signaling cascades are not point-to-point linear paradigms but involve complex cross-talking, we thus decided to find a new way to examine this relationship. Functional proteomics is an emerging technology to study the molecular mechanisms of cell function and is an ideal tool for clarifying unbiased and large-scale quantitative protein changes under physiological and diseased 
conditions. This tool offers us another way of discovering novel or rarely studied proteins that are associated with changes in cell structure and function. Although proteomic analysis is now widely used in many clinical or basic medical research fields, it is rarely used for diabetes research, particularly for studying PKC- $\delta$-induced apoptosis in human umbilical vein endothelial cells (HUVECs). Thus, proteomic analysis is a creative way to further study the downstream effectors of PKC- $\delta$ signaling in its proapoptotic function.

\section{Materials and methods}

Cell culture and reagents. HUVECs were preserved by the Institute of Biological Sciences of Chongqing Medical University (Chongqing, China) and cultured in RPMI-1640 medium (Gibco, Carlsbad, CA, USA) supplemented with $10 \%$ fetal bovine serum (Gibco) and antibiotics. Prior to the start of the experiment, cells were kept subconfluent and grown for 1 to 2 days in an atmosphere containing $5 \% \mathrm{CO}_{2} / 95 \%$ ambient air at $37^{\circ} \mathrm{C}$. To optimize cell responsiveness to conditions of high glucose, cells were serum-starved for $24 \mathrm{~h}$ prior to the start of the experiment.

Recombinant adenovirus-infected HUVECs and treatment. A recombinant adenoviral vector was constructed to express PKC- $\delta$ and packaged at a titer of $1.9 \times 10^{11} \mathrm{vp} / \mathrm{ml}$ Ad5-PKC $\delta$ with a multiplicity of infection (MOI) of 10 based on preliminary experiments. As the control, Ad5-Null was used as an empty vector to infect cells. Cells transfected either with or without adenovirus were cultured in RPMI-1640 medium containing either 5.6 or $25 \mathrm{mmol} / \mathrm{l}$ glucose; the high glucose medium also contained $10 \mu \mathrm{mol} / \mathrm{l}$ of rottlerin. The medium was changed every 2 days for a total of 6 days. Subcultures of passage 10 to 15 were used for all proteomic analyses; passages 5 to 10 were used for confocal imaging and apoptosis assays.

Immunofluorescence labeling of PKC- $\delta$ and confocal microscopy. Cells were cultured on glass coverslips (10 mm diameter) in 6-well culture plates and fixed with $4 \%$ paraformaldehyde (15 min at room temperature), followed by membrane permeabilization with $0.2 \%$ Triton-X $100\left(10 \mathrm{~min}\right.$ at $\left.4^{\circ} \mathrm{C}\right)$. After washing three times with PBS, cells were blocked with $1 \%$ goat serum and $0.1 \%$ bovine serum albumin in PBS $(60 \mathrm{~min}$ at room temperature). For immunoblotting studies, a PKC- $\delta$ polyclonal antibody (Santa Cruz, USA) was diluted 1:100 in blocking solution and added to each coverslip (overnight at $4^{\circ} \mathrm{C}$ ). After washing three times with PBS, the cells were incubated with the secondary antibody (FITC-conjugated goat anti-rabbit IgG) diluted 1:160 in blocking solution and incubated in the dark $\left(2 \mathrm{~h}\right.$ at $\left.37^{\circ} \mathrm{C}\right)$. Coverslips were subsequently washed three times with PBS and mounted onto glass slides using 50\% glycerol. The fluorescence intensity of PKC- $\delta$ in both the cytosol and nucleus was monitored at an excitation wavelength of $488 \mathrm{~nm}$ using a fluorescein isothiocyanate filter (Leica, Germany). The average absolute fluorescence intensities of labeled PKC- $\delta$ for 20-30 cells per experimental group were analyzed and the data were pooled from 3-4 consecutive experiments.

Cell cycle assays. After incubation in culture medium for 6 days, the cells were harvested by trypsinization, resuspended in PBS at a concentration of $1 \times 10^{5} / \mathrm{ml}$ and fixed in ice-cold $75 \%$ ethanol $\left(30 \mathrm{~min}\right.$ at $\left.4^{\circ} \mathrm{C}\right)$. Cells were then washed twice in cold PBS, treated with $20 \mu \mathrm{g} / \mathrm{ml}$ RNase A (30 min at room temperature) and stained with $50 \mu \mathrm{g} / \mathrm{ml}$ propidium iodide (PI). Finally, cells were resuspended in $1 \mathrm{ml}$ of PBS and analyzed by flow cytometry according to the manufacturer's instructions.

Apoptosis assays. Apoptosis rates were measured using the Annexin V-FITC Cell Apoptosis kit (Abcam, USA). For measuring early or late/necrotic apoptotic cell death, approximately $1-5 \times 10^{5}$ cells were stained with $5 \mu \mathrm{l}$ of FITC-labeled Annexin-V and PI in $500 \mu \mathrm{l}$ of binding buffer and analyzed by flow cytometry following the manufacturer's instructions. Annexin V and PI emissions were detected in the FL1 and FL2 channels of a FACScalibur flow cytometer using emission filters of 488 and $532 \mathrm{~nm}$, respectively.

Nuclear protein extraction. To exclude the empty vector interference, we added an empty vector group, which consisted of cells transfected with Ad5-Null and cultured in high glucose conditions $(25 \mathrm{mmol} / \mathrm{l})$. Cells from the normal control group, high glucose group, PKC- $\delta$ overexpression group and the empty vector group under high glucose were used to observe the differential expression of proteins associated with PKC- $\delta$ under conditions of high glucose. Nuclei were purified using an improved protocol by Turck et al (18). Briefly, cells suspensions were centrifuged at $800 \mathrm{x} \mathrm{g}$ for $10 \mathrm{~min}$ at $4^{\circ} \mathrm{C}$. After discarding the supernatant, the cell pellet was resuspended in lysis buffer [0.5\% NP-40 (Sigma), $5 \mathrm{mM} \mathrm{MgCl}, 10 \mathrm{mM} \mathrm{NaCl}, 5 \mathrm{mM}$ Tris- $\mathrm{HCl}, \mathrm{pH} 7.5,10 \%$ (v/v) glycerol, $1 \mathrm{mM}$ DTT and $1 \mathrm{mM}$ PMSF], placed on ice for $10 \mathrm{~min}$ and then centrifuged for $5 \mathrm{~min}$ at $800 \mathrm{x} \mathrm{g}$ at $4^{\circ} \mathrm{C}$, this step was repeated twice. The nuclei pellet was resuspended in $0.25 \mathrm{M}$ sucrose, layered on a $2 \mathrm{M}$ sucrose cushion in $1 \mathrm{mM} \mathrm{MgCl}$ and $20 \mathrm{mM}$ Tris ( $\mathrm{pH}$ 7.5) and centrifuged for $30 \mathrm{~min}$ at $100,000 \mathrm{x} \mathrm{g}$ at $4^{\circ} \mathrm{C}$. The nuclei pellet was resuspended in 2-D buffer containing $7 \mathrm{M}$ urea, $2 \mathrm{M}$ thiourea, $4 \%$ CHAPS and $20 \mathrm{mM}$ DTT. To precipitate the DNA, $10 \mathrm{mM}$ spermine were added to the suspension for $1 \mathrm{~h}$ at room temperature. The suspension was then placed into liquid nitrogen to freeze/thaw three times and centrifuged at $12,000 \mathrm{x} \mathrm{g}$ for $30 \mathrm{~min}$ to recover the supernatant containing nuclear proteins. Protein concentration was quantified using the Bio-Rad RC DC Protein Assay kit (Bio-Rad, Hercules, CA, USA). The sample was aliquoted and stored at $-80^{\circ} \mathrm{C}$.

Two-dimensional electrophoresis. The cell lysate containing nuclear protein $(300 \mu \mathrm{g})$ was added to rehydration buffer (final volume of $400 \mu \mathrm{l}$ ), and 1\% (w/v) DTT and ampholytes were added prior to use. ReadyStrip IPG strips [pH 3-10, $17 \mathrm{~cm}$, unlined (Bio-Rad)] were passively rehydrated for $12 \mathrm{~h}$ continuously at $17^{\circ} \mathrm{C}$, followed by isoelectric focusing (IEF) in a stepwise fashion: $250 \mathrm{~V}$ for $2 \mathrm{~h}, 500 \mathrm{~V}$ for $1 \mathrm{~h}, 1000 \mathrm{~V}$ for $1 \mathrm{~h}$ (rapidly), 10,000 V for $6 \mathrm{~h}$, and focused for a total of 70,000 Vh. The focused strips were then incubated twice with equilibration buffer for $15 \mathrm{~min}$ each at room temperature; $1 \%(\mathrm{w} / \mathrm{v})$ DTT was added to the first incubation and replaced by $2.5 \%$ $(\mathrm{w} / \mathrm{v})$ iodoacetamide in the second incubation. The equilibrated strips were then transferred to a two-dimensional, 1-mm thick SDS-PAGE gel and sealed in place with $1 \%$ low melting point agarose. The $10 \%$ acrylamide gradient gel was run at $60 \mathrm{~V}$ for 

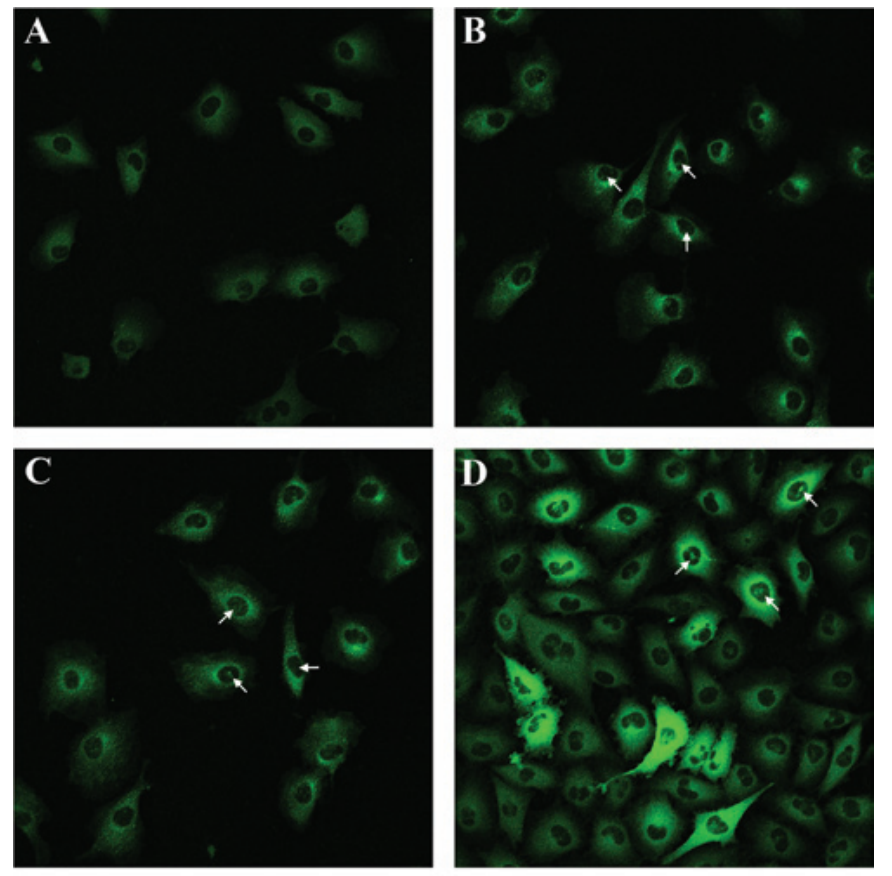

$\mathbf{E}$

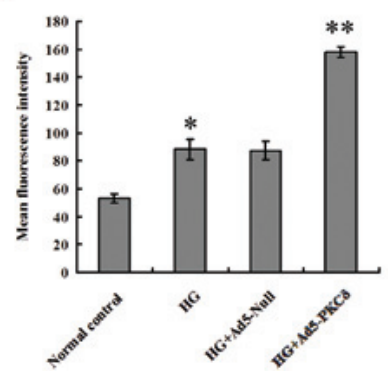

$\mathbf{F}$

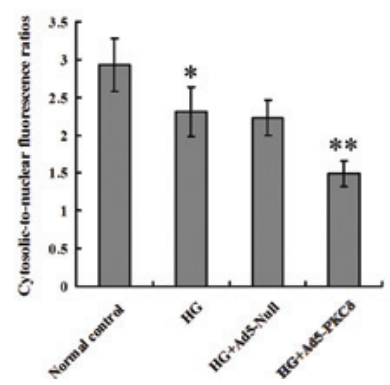

Figure 1. Expression and distribution of PKC- $\delta$. The expression and distribution of PKC- $\delta$ in (A) the normal control group (5.6 mmol/1 glucose), (B) the high glucose group ( $25 \mathrm{mmol} / 1$ glucose), (C) the empty vector control group (25 mmol/1 glucose + Ad5-null), and (D) the PKC- $\delta$ overexpression group (25 mmol/1 glucose + Ad5-PKC $)$, by confocal microscopy (x400) Green fluorescence represents the abundance of PKC- $\delta$ protein in HUVECs. Images show increased $\mathrm{PKC}-\delta$ expression and nuclear translocation in HUVECs with $25 \mathrm{mmol} / 1$ glucose exposure. White arrows indicate increased nuclear fluorescence. (E) The mean fluorescence intensity of cells among the four groups. ${ }^{*} \mathrm{p}<0.05$ vs. normal control group; ${ }^{* *} \mathrm{p}<0.05$ vs. high glucose group, $n=5$. (F) Cytosolic-to-nuclear fluorescence ratios. ${ }^{*} \mathrm{p}<0.05$ vs. normal control; ${ }^{* *} \mathrm{p}<0.05$ vs. high glucose group, $\mathrm{n}=5$. HG, high glucose.

$30 \mathrm{~min}$, followed by $200 \mathrm{~V}$ for $7 \mathrm{~h}$ at $16^{\circ} \mathrm{C}$ using the Protean II cell (Bio-Rad) with $17-\mathrm{cm}$ strips. Nuclear proteins were stained with silver nitrate (according to the Bio-Rad operating manual) because the amount of nuclear protein extracted from HUVECs was relatively low, and this method is compatible with MS analysis. Protein spots were analyzed using PDQuest Image Analysis software version 9.0 (Bio-Rad).

Preparation of peptide sample and database search. Protein spots of interest were excised from the gel with a sterile blade and washed three times with Milli-Q water. After a series of decoloring treatments, dehydration and rehydration, the gel spots were digested with trypsin for $16-24 \mathrm{~h}$ at $37^{\circ} \mathrm{C}$. The supernatant containing the tryptic peptide mixtures was lyophilized. For concentrating and purifying peptide samples, we used ZipTip C18 pipette tips (Millipore, Billerica, MA, USA) according to the manufacturer's instructions. Lastly, matrix solution was added before submitting samples for matrix-assisted laser desorption/ ionization time of flight mass spectrometry (MALDI-TOF-MS). Monoisotopic peptide masses were assigned and used for database searches. Data files were then fed into the Mascot search engine (Matrix science, London, UK) and searched against an NCBI non-redundant protein sequence database (released November 30, 2009). We allowed one possible missed cleavage site in the search parameters for incomplete trypsin digestion, and oxidation (M) and carbamidomethyl (C) were selected as variable and fixed modifications, respectively. The peptide mass error was limited to $50 \mathrm{ppm}$. A minimum of four matching peptides was required to assign identity; protein scores $>56$ were considered significant $(\mathrm{P}<0.05)$. Furthermore, theoretical and experimental molecular weight (Mr) and isoelectric point (pI) must be in general correlation.

Statistical analyses. Measurement data were expressed as the means \pm standard deviation (SD). Data from apoptosis or cell cycle assays were analyzed using analysis of one-way variance (ANOVA) and the SNK-q test to further compare between the two groups.

2-DE quantitative comparison was performed using the PDQuest software. The spot volume was expressed as a numeric value of optical density. We used the two independent groups t-test for intergroup comparisons. All statistical analyses were performed with the SPSS software version 11.0, and a value of $\mathrm{P}<0.05$ was considered statistically significant.

\section{Results}

Up-regulation and nuclear translocation of PKC- $\delta$ in HUVECs under high glucose stress. To determine the effect of high glucose on PKC- $\delta$ expression in HUVECs, we used immunofluorescence (with an isoform-specific antibody) and confocal microscopy to detect PKC- $\delta$. Under basal conditions, PKC- $\delta$ displayed a homogeneous distribution in the cytoplasm of HUVECs, with little PKC- $\delta$ fluorescence in the nucleus (Fig. 1A). However, in the presence of high glucose, the fluorescence intensity per cell increased 1.6-fold in the cytoplasm and the cytosolic-to-nuclear fluorescence ratio decreased (Fig. 1B). As the control, the Ad5-Null empty vector was transfected into cells (Fig. 1C), and as expected, it did not produce any obvious differences. Quantity and distribution of fluorescence were the same in cells either transfected with or without the Ad5-null vector in response to $25 \mathrm{mmol} / \mathrm{l}$ high glucose. As expected, when PKC- $\delta$ was overexpressed (Fig. 1D), the fluorescence intensity per cell after adenovirus transfection was significantly increased 1.8-fold compared to that of the non-transfected high glucose control $(\mathrm{P}<0.05)$, whereas the cytosolic-to-nuclear PKC- $\delta$ fluorescence ratio markedly decreased (PO vs HG, $1.49 \pm 0.17$ vs. 2.31 \pm 0.33 ; $\mathrm{P}<0.05)$. Together, these findings demonstrate that PKC- $\delta$ protein levels and activation (or translocation into the nucleus) in HUVECs were significantly increased with high glucose exposure. The import of ectogenic PKC- $\delta$ seemed to improve this tendency in the presence of high glucose.

Activation of PKC- $\delta$ induces cell cycle arrest and apoptosis in HUVECs under high glucose stress. We used flow cytometric 
Table I. Cell cycle distribution in the various groups.

\begin{tabular}{lcrc}
\hline Group & $\mathrm{G}_{0} / \mathrm{G}_{1}$ & $\mathrm{~S}$ & \multicolumn{1}{c}{$\mathrm{G}_{2} / \mathrm{M}$} \\
\hline $\mathrm{NC}$ & $59.81 \pm 2.04$ & $18.62 \pm 2.86$ & $21.56 \pm 3.34$ \\
$\mathrm{EC}$ & $68.67 \pm 3.45$ & $13.10 \pm 6.19$ & $18.23 \pm 2.80$ \\
$\mathrm{HG}$ & $75.83 \pm 2.51^{\mathrm{a}}$ & $10.73 \pm 3.88$ & $13.44 \pm 1.94$ \\
PO & $80.41 \pm 0.72^{\mathrm{b}}$ & $8.49 \pm 2.21$ & $11.10 \pm 2.06$ \\
PI & $65.21 \pm 4.95^{\mathrm{c}}$ & $15.27 \pm 5.34$ & $19.52 \pm 2.75$ \\
\hline
\end{tabular}

The majority of cells were in the $\mathrm{G}_{0} / \mathrm{G}_{1}$ phase in the normal glucose control group (NC), high glucose group (HG), empty vector control group (EC), PKC- $\delta$ overexpression group (PO) and PKC- $\delta$ inhibition group (PI). High glucose $(25 \mathrm{mmol} / \mathrm{l})$ induced significant cell cycle arrest at the $\mathrm{G}_{0} / \mathrm{G}_{1}$ phase (HG vs. $\mathrm{NC},{ }^{\mathrm{a}} \mathrm{p}<0.05$ ); the cell cycle arrest appeared to be more severe when transfected with Ad5- PKC $(\mathrm{PO}$ vs. $\left.\mathrm{HG},{ }^{\mathrm{b}} \mathrm{p}<0.05\right)$. After incubation with the PKC- $\delta$-specific inhibitor, rottlerin $(10 \mu \mathrm{mol} / \mathrm{l})$, cell cycle arrest was significantly improved (PI vs. $\left.\mathrm{PO},{ }^{\mathrm{c}} \mathrm{p}<0.05\right)$, whereas no significant difference was observed when cells were transfected with the empty vector in $25 \mathrm{mmol} / \mathrm{l}$ glucose (EC vs. HG, $\mathrm{p}>0.05$ ).

analysis to determine which cell cycle phase was affected by high glucose exposure and whether PKC- $\delta$ activation exhibits proapoptotic effects in HUVECs (Table I and Fig. 2). Our team found that approximately $4.1 \pm 0.67 \%$ of cells underwent early apoptosis in response to $5.6 \mathrm{mmol} / 1$ glucose exposure for 6 days, whereas approximately $22 \pm 2.7 \%$ of cells were early apoptotic in the presence of $25 \mathrm{mmol} / 1$ glucose. In addition, high glucose exposure arrested cells in the $G_{0} / G_{1}$ phase of the cell cycle (Table $\mathrm{I}$ ), as the percentage of $\mathrm{G}_{0} / \mathrm{G}_{1}$ cells was approximately 1.3 -fold higher in $25 \mathrm{mmol} / \mathrm{l}$ glucose than in $5.6 \mathrm{mmol} / \mathrm{l}$ glucose. However, cells transfected either with or without an Ad5-Null empty vector cultured under high glucose conditions did not show any significant difference in either the apoptotic ratio or cell cycle distribution $(\mathrm{P}>0.05)$. To test whether PKC- $\delta$ modulates high glucose-induced cell cycle arrest and apoptosis, we also inhibited and overexpressed PKC- $\delta$. We treated cells with the PKC- $\delta$ selective inhibitor, rottlerin $(10 \mu \mathrm{mol} / \mathrm{l})$ and found that the basal level of cell apoptosis was significantly affected at $25 \mathrm{mmol} / 1$ glucose, reducing cell apoptosis by approximately $80 \%$. However, as the in vitro inhibitory effect of rottlerin on PKC- $\delta$ activity is controversial $(19,20)$, we further explored the role of PKC- $\delta$ in apoptosis and cell cycle arrest by overexpressing PKC- $\delta$ using an adenovirus. As demonstrated above, infection of an adenovirus vector encoding wild-type PKC- $\delta$ resulted in a moderate overexpression of PKC- $\delta$ compared with the null vector control. This level of overexpression increased PKC- $\delta$ kinase activity in the particulate fraction by translocating PKC- $\delta$ from the cytosol into the nucleus. Furthermore, PKC- $\delta$ overexpression also led to cell cycle arrest and significantly increased the rate of high glucose-induced apoptosis $(\mathrm{P}<0.05)$. These findings suggest that high glucose induces cell cycle arrest at the $G_{0} / G_{1}$ phase and apoptosis in HUVECs, further indicating that PKC- $\delta$ is an important signaling modulator that mediates these cellular processes under conditions of high glucose.

Two-dimensional electrophoresis of nuclear proteins from HUVECs. Differences in protein expression under several different conditions were quantified and comparatively processed. Differences $>1.5$-fold in optical density between the groups were considered statistically significant. To screen for differential protein expression in the spots, a three-step comparison was performed.

i) To screen for differential protein expression in spots induced by high glucose stress, we performed two-dimensional electrophoresis of nuclear proteins from cells in the normal control and high glucose groups. Intergroup statistical analyses detected 56 altered nuclear spots.

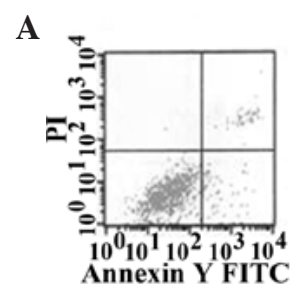

D

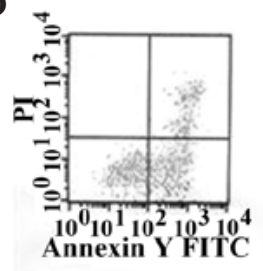

B

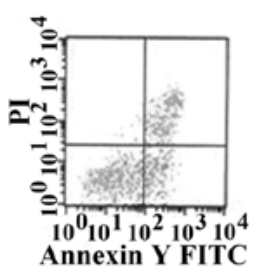

C

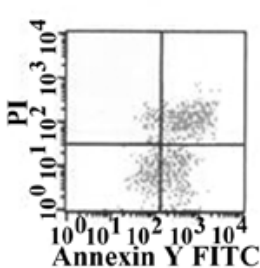

E

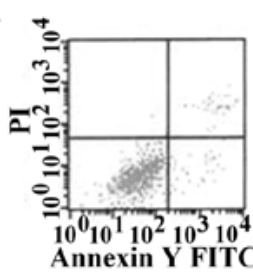

F

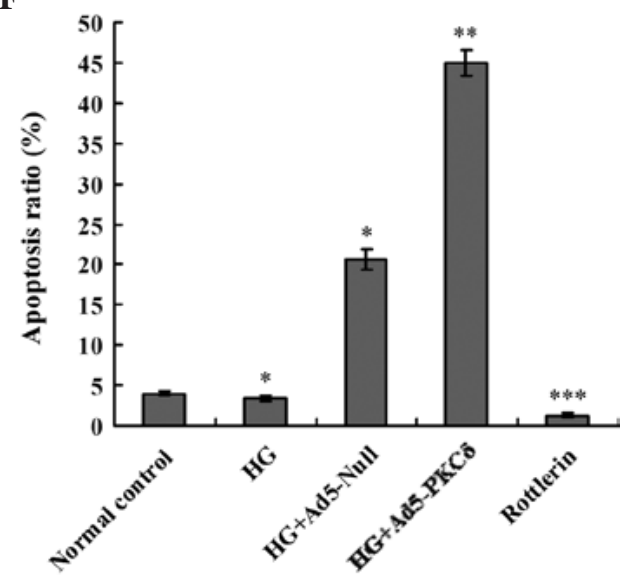

Figure 2. Apoptosis ratios in the various groups. Cells were cultured in (A) normal glucose, (B) high glucose, (C) high glucose + Ad5-null, (D) high glucose + Ad5-PKCס and (E) high glucose + rottlerin. A cytogram of cells undergoing apoptosis shows that the early apoptotic cells located in the lower right quadrant were Annexin V-positive and PI-negative; late apoptotic or necrotic cells located in the upper right quadrant were Annexin V-positive and PI-positive; live cells located in the lower left quadrant were negative for both fluorescent probes. (F) Apoptotic ratios in the various groups. The apoptotic ratio of cells in $25 \mathrm{mmol} / 1$ glucose increased 2-fold compared to cells in $5.6 \mathrm{mmol} / 1$ glucose $\left({ }^{*} \mathrm{p}<0.05\right)$; a similar result was observed in cells transfected with Ad5-null in high glucose $(* \mathrm{p}<0.05)$, but no significant change was observed even when the empty vector effect was considered. Furthermore, the apoptotic ratio of cells with overexpressed PKC- $\delta$ in $25 \mathrm{mmol} / 1$ glucose was remarkably high $\left({ }^{* *} \mathrm{p}<0.05\right)$, whereas the percentage of cells in early apoptosis decreased back to normal control levels when PKC- $\delta$ expression was partially inactivated by rottlerin $(10 \mu \mathrm{mol} / \mathrm{l})\left({ }^{*} * * * 0.05\right)$. HG, high glucose. 
Table II. Nuclear proteins from HUVECs identified by peptide mass fingerprinting.

\begin{tabular}{|c|c|c|c|c|}
\hline $\begin{array}{l}\text { SWISS-PROT } \\
\text { Accession no. }\end{array}$ & Protein name & $\begin{array}{c}\text { Sequence coverage } \\
(\%)\end{array}$ & Mass & pI \\
\hline 1. Q0VDF9.1 & Heat shock $70 \mathrm{kDa}$ protein 14 & 14 & 55 & 5.41 \\
\hline 2. Q8WW36.1 & Zinc finger $\mathrm{CCHC}$ domain-containing protein 13 & 34 & 19 & 9.33 \\
\hline 3. Q9H788.1 & $\mathrm{SH} 2$ domain-containing protein $4 \mathrm{~A}$ & 24 & 53 & 8.09 \\
\hline 4. Q49AA0.2 & Zinc finger protein 642 & 18 & 62 & 8.78 \\
\hline 5. P49336.1 & Cell division protein kinase 8 & 13 & 54 & 8.72 \\
\hline 6. O60812.1 & Heterogeneous nuclear ribonucleoprotein C-like 1 & 20 & 32 & 4.93 \\
\hline 7.P30281.2 & $\mathrm{G}_{1} / \mathrm{S}$-specific cyclin-D3 & 20 & 33 & 6.66 \\
\hline 8.075688 .1 & Protein phosphatase 1B & 26 & 53 & 4.95 \\
\hline 9. P30304.2 & M-phase inducer phosphatase 1 & 27 & 60 & 6.49 \\
\hline 10. Q96N38.1 & Zinc finger protein 714 & 20 & 66 & 9.29 \\
\hline 11. P12004.1 & Proliferating cell nuclear antigen & 37 & 29 & 4.57 \\
\hline 12. Q9UJW8.2 & Zinc finger protein 180 & 22 & 81 & 8.04 \\
\hline 13. P42771.2 & Cyclin-dependent kinase inhibitor 2A & 28 & 17 & 5.52 \\
\hline 14. Q13330.1 & Metastasis-associated protein 1 & 16 & 81 & 9.40 \\
\hline 15. P28072.4 & Proteasome subunit $\beta$ type- 6 & 26 & 26 & 4.80 \\
\hline 16. Q5TKA1.1 & Lin-9 homolog & 14 & 62 & 9.17 \\
\hline 17. Q8WWW0.1 & Ras association domain-containing protein 5 & 21 & 48 & 9.31 \\
\hline 18. Q13838.1 & Spliceosome RNA helicase BAT1 & 28 & 49 & 5.44 \\
\hline 19. O00141.2 & Serum and glucocorticoid-inducible kinase 1 & 21 & 49 & 8.71 \\
\hline 20. P40692.1 & DNA mismatch repair protein Mlh1 & 12 & 85 & 5.51 \\
\hline 21. Q6ZN06.2 & Zinc finger protein 813 & 12 & 74 & 9.50 \\
\hline 22. P10809.2 & $60 \mathrm{kDa}$ heat shock protein & 24 & 61 & 5.71 \\
\hline 23. Q9GZM3.1 & DNA-directed RNA polymerase II subunit RPB11-b1 & 46 & 53 & 5.88 \\
\hline 24. P47755.3 & F-actin-capping protein subunit $\alpha-2$ & 28 & 33 & 5.57 \\
\hline 25. Q14147.1 & Probable ATP-dependent RNA helicase DHX34 & 15 & 65 & 9.16 \\
\hline 26. P11021.2 & 78-kDa glucose-regulated protein & 24 & 72 & 5.07 \\
\hline 27. Q6R2W3.1 & SCAN domain-containing protein 2 & 23 & 35 & 10.66 \\
\hline 28. Q8NEU8.3 & DCC-interacting protein $13-\beta$ & 21 & 75 & 4.87 \\
\hline 29. P06493.1 & Cell division control protein 2 homolog & 26 & 34 & 8.37 \\
\hline 30. Q9NWT1 & P21-activated protein kinase-interacting protein 1 & 20 & 45 & 9.07 \\
\hline 31. Q5TIS6.1 & Homeobox protein notochord & 12 & 27 & 9.43 \\
\hline 32. Q92481.2 & Transcription factor AP-2B & 13 & 51 & 8.41 \\
\hline 33. P49759.2 & Dual specificity protein kinase CLK1 & 15 & 58 & 9.05 \\
\hline 34. Q9BZE4.3 & Nucleolar GTP-binding protein 1 & 18 & 62 & 8.09 \\
\hline 35. Q8TC84.3 & Fibronectin type 3 and ankyrin repeat domains protein 1 & 20 & 39 & 8.93 \\
\hline 36. AAW67758.1 & Nucleophosmin & 25 & 33 & 4.64 \\
\hline 37. P23193.2 & Transcription elongation factor A protein 1 & 20 & 34 & 8.64 \\
\hline
\end{tabular}

The characteristics of all the identified proteins containing the protein name, protein database accession number, percentage of sequence coverage, mass and isoelectric point (pI) are listed.

ii) To quantify the altered protein spots induced by $\mathrm{PKC}-\delta$ activation, nuclear proteins from cells transfected with either Ad5-PKCס or Ad5-null cultured in $25 \mathrm{mmol} / 1$ glucose medium were each dispersed on the gels, and intergroup crossmatching identified 67 spots.

iii). The 51 common protein spots found in steps i) and ii) by intergroup comparison were screened and defined as PKC- $\delta$-associated proteins under high glucose stress.

All 51 spots were screened by the three-step comparison, as satisfactory MALDI-MS spectra were obtained. We then searched databases by peptide mass fingerprinting (detailed in Materials and methods). Finally, we identified 37 types of proteins that corresponded to 37 different proteins. As shown in
Fig. 3, we detected a total of $\sim 600$ protein spots in each gel. The percentage of sequence coverage calculated by MALDI-MS was between 10 and $50 \%$, and reproducible results were obtained for the three gels analyzed. The characteristics of all possible proteins, including the protein name, protein database accession number, percentage of sequence coverage, protein mass, $\mathrm{pI}$ and any known function are listed in Tables II and III.

\section{Discussion}

In the present study, we established a model of constitutively active PKC- $\delta$ in HUVECs exposed to high ambient glucose levels, which partially simulates the molecular events of 
Table III. Proteins involved in apoptosis and cell cycle regulation.

\begin{tabular}{lll}
\hline Spot code Protein name Protein function & Par
\end{tabular}

7

$\mathrm{G}_{1} / \mathrm{S}$-specific cyclin-D3

(CCND3)

13

Cyclin-dependent kinase inhibitor 2A

(CDKN2A)

16

Lin-9 homolog

(hLin-9)

17

Ras association domain-containing protein 5

(RAPL)

Serum and glucocorticoid-inducible kinase 1

(SGK1)
This cyclin forms a complex with and functions as a regulatory subunit of CDK4 or CDK6, which is required for the $\mathrm{G}_{1} / \mathrm{S}$ transition. Shown to interact with and phosphorylate the $\mathrm{Rb}$ tumor suppressor.

Encodes proteins that regulate the p53 and retinoblastoma pathways. The CDKN2A gene produces two major proteins: $\mathrm{p} 16$

(a cyclin-dependent kinase inhibitor) and p14 (which binds the p53-stabilizing protein MDM2).

Acts as a tumor suppressor and inhibits DNA synthesis. The ability to inhibit oncogenic transformation is mediated through its association with RB1. Plays a role in the expression of genes required for the $\mathrm{G}_{1} / \mathrm{S}$ transition.

Potential tumor suppressor. May be involved in regulation of Ras apoptotic function. The RASSF5-STK4 complex may mediate HRAS1- and KRAS-induced apoptosis.

Plays an important role in cellular stress response, cell survival, neuronal excitability and renal sodium excretion. Sustained high levels and activity may contribute to hypertension and diabetic nephropathy. Mediates cell survival, phosphorylates and negatively regulates the proapoptotic protein FOXO3A.

Possibly plays a role in the assembly of multimeric protein complexes inside the ER.

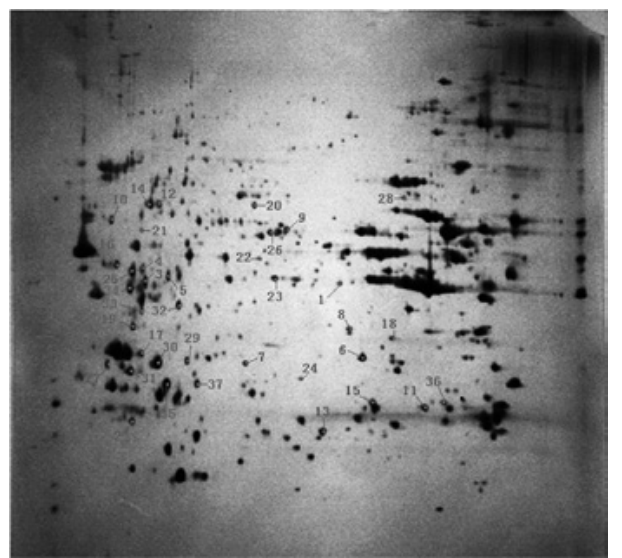

Figure 3. 2-D gel of nuclear proteins in HUVECs from each group. 2-D gel of nuclear proteins in HUVECs from each group. Nuclear proteins $(200 \mu \mathrm{g})$ were focused onto a ReadyStrip IPG strip ( $\mathrm{pH} 3-10,17 \mathrm{~cm}$, unlined) prior to separation on a $10 \%$ SDS-PAGE gel.

vascular complication in type 1 or type 2 diabetes. We are the first to use a novel functional proteomics approach to systemically delineate the PKC- $\delta$-associated nuclear protein profile for HUVECs under high glucose stress. More importantly, we found that the recruitment of nuclear proteins into the PKC- $\delta$ signaling network is highly related to hyperglycemia-induced cell apoptosis and cell cycle arrest. We explored both the differential nuclear protein expression of HUVECs in response to high glucose and that of constitutively active PKC- $\delta$. Simultaneous comparison of the gels identified 51 differentially expressed proteins that were significantly altered by high glucose and modulated by constitutively active PKC- $\delta$. This is the first strategy to analyze interactions between a signaling kinase and nuclear proteins. Finally, we classified all identified proteins according to their known functions in a) cell cycle and apoptosis regulation, b) tumor suppression, c) transcription, d) stress and e) signal transduction within the nucleus.

Many of the nuclear proteins found to be associated with PKC- $\delta$ in our study were not previously known or suspected to interact with PKC- $\delta$. Notably, among all the identified proteins, serum/glucocorticoid-regulated kinase 1 (SGK1, also known as serine/threonine-protein kinase 1) had not previously been reported as a functional downstream effector of PKC- $\delta$ signaling. As a protein kinase, SGK1 plays an important role in the cellular stress response and may be involved in the regulation of other processes, such as cell survival, neuronal excitability, and renal sodium excretion $(21,22)$. Sustained high levels and activity of SGK1 may contribute 
to conditions, such as hypertension and diabetic nephropathy (23). It also mediates cell survival signals, phosphorylates and negatively regulates the proapoptotic FOXO3A protein (24). SGK1 has been reported to play an important role in diabetic nephropathy, as it was shown to be activated in response to a variety of extracellular stimuli (22). In addition, SGK1 is related to Akt, is activated by phosphoinositide-3 kinase $(\mathrm{PI} 3 \mathrm{~K})$ and translocates to the nucleus where it may further mediate cell survival and cell cycle progression through its downstream effector, FOXO3A. Our proteomic analysis revealed a quantitative change in SGK1 in the nucleus that appeared to be associated with the overexpression of PKC- $\delta$, a novel finding suggesting that PKC- $\delta$ may act upstream of SGK1 but not Akt/PI3K (also called PKB). We know that both PKC $-\delta$ and PKB belong to a family of protein kinases that promotes a variety of biological responses by phosphorylating individual or common substrates at different regulatory sites. PKC- $\delta$ also directly regulates PKB activity and participates in the Akt/PI3K signaling pathway in the cytoplasm. Although the underlying mechanism of this activity is unknown, we speculate that PKC- $\delta$ may phosphorylate SGK1 after translocation into the nucleus or indirectly impact SGK1 activity through PKB signaling pathway in the cytoplasm.

Cyclin-dependent kinase inhibitor 2A (CDKN2A) is another protein we found by MS based on its quantitative change in response to high glucose. The alpha transcript of CDKN2A encodes p16, a recognized tumor suppressor that induces $\mathrm{G} 1$ cell cycle arrest by inhibiting the phosphorylation of the Rb protein by the cyclin-dependent kinases, CDK4 and CDK6. Wolf et al (25) detected high protein expression levels of glomerular p16INK4 and p27Kip1 in diabetic BBdp rats. Although CDKN2A is one of several previously unsuspected genes associated with type 2 diabetes (T2D) identified by genome-wide association (GWA) studies, Sanghera et al reported that a CDKN2A SNP found in Asian Indian Sikhs was not associated with type 2 diabetes (26).

The $\mathrm{G}_{1} / \mathrm{S}$-specific cyclin D3 (CCND3 gene) is known to play a crucial role not only in the progression through the $\mathrm{G} 1$ phase as a regulatory subunit of CDK4 and CDK6 but also in many other processes, such as cell cycle progression, cellular differentiation, transcriptional regulation and apoptosis. In addition, cyclin D3 is essential for the regulation of the cell cycle at the $G_{1} / S$ transition and may potentially play a role as a transcriptional regulator by interacting with human activating transcription factor 5 (ATF5) (27). Although previous proteomic analyses (28) have found that apoptosis in tumor cells is accompanied by increased levels of the CCND3 gene, no significant correlation has been observed. Our data show that, in high glucose conditions, the activation of PKC- $\delta$ may be one of the initial factors in cyclin D3-dependent cell apoptosis and cell cycle arrest.

As high glucose was able to cause apoptosis and cell cycle arrest in HUVECs during the $\mathrm{G}_{0} / \mathrm{G}_{1}$ phase as well as to induce PKC- $\delta$ translocation into the nucleus, we hypothesized that PKC- $\delta$ might be an important mediator of apoptosis and cell cycle arrest. This hypothesis was supported by the use of the PKC- $\delta$ inhibitor, rottlerin, and more specifically, by the fact that HUVECs overexpressing wild-type PKC- $\delta$ are more intolerant to high glucose-induced apoptosis and cell cycle arrest. It is well established that apoptosis may be induced by
PKC- $\delta$ activation via internal signals, such as cytochrome $\mathrm{c}$ and apoptosis-inducing factors released from the mitochondria. However, our results indicate that the mitochondria are not the only targets of PKC- $\delta$. There is likely another important intracellular apoptotic signaling pathway characterized by the nuclear translocation of PKC- $\delta$, although the sensitivity of immunofluorescence and confocal microscopy does not exclude that PKC- $\delta$ may also transiently translocate to the mitochondrial membrane. Our proteomics results indicate that the nuclear proteins, SGK1, CDKN2A, the CCND3 gene, and M-phase inducer phosphatase 1 , may act downstream of PKC- $\delta$. However, it is still unknown which protein plays the most dominant role in maintaining the balance between cell death and survival, and further study is required in order to elucidate the underlying mechanisms in this network of protein interactions.

In conclusion, our data show that PKC- $\delta$ is an important mediator of cell apoptosis and cell cycle arrest in HUVECs under high glucose stress through diverse downstream effectors, such as SGK1, CCND3, CDKN2A, hLin-9, RAPL and 78-kDa glucose-regulated protein (GRP78). Cell apoptosis occurs as an initial event in diabetic vascular complications, and the mechanism of this cell death is not completely understood. Therefore, our findings provide new insight into the mechanism of diabetes-associated blood vessel damage, indicating that specific inhibitors of PKC- $\delta$ or its key downstream effectors may be potential therapeutic agents to prevent macro- and microvascular diabetic complications in humans.

\section{Acknowledgements}

This study was supported by the National Natural Science Foundation of China (no. 30570877). The authors would like to acknowledge support from the Ophthalmology Laboratory of Chongqing Medical University, and also to thank Dr Liming Mao for his 2-D technological support and Dr Mingjun Wu for his help in MS analysis.

\section{References}

1. Bakker W, Eringa EC, Sipkema P and van Hinsbergh VW: Endothelial dysfunction and diabetes: roles of hyperglycemia, impaired insulin signaling and obesity. Cell Tissue Res 335: 165-189, 2009.

2. Orasanu G and Plutzky J: The pathologic continuum of diabetic vascular disease. J Am Coll Cardiol 53: S35-S42, 2009.

3. Srivastava S, Ramana KV, Tammali R, Srivastava SK and Bhatnagar A: Contribution of aldose reductase to diabetic hyperproliferation of vascular smooth muscle cells. Diabetes 55: 901-910, 2006.

4. Chan KC, Wang CJ,Ho HH, Chen HM and Huang CN: Simvastatin inhibits cell cycle progression in glucose-stimulated proliferation of aortic vascular smooth muscle cells by up-regulating cyclin dependent kinase inhibitors and p53. Pharmacol Res 58: 247-256, 2008.

5. Li Y, Wu H, Khardori R, Song YH, Lu YW and Geng YJ: Insulin-like growth factor-1 receptor activation prevents high glucose-induced mitochondrial dysfunction, cytochrome-c release and apoptosis. Biochem Biophys Res Commun 384: 259-264, 2009.

6. Simone S, Gorin Y, Velagapudi C, Abboud HE and Habib SL: Mechanism of oxidative DNA damage in diabetes: tuberin inactivation and downregulation of DNA repair enzyme 8-oxo7,8-dihydro-2'-deoxyguanosine-DNA glycosylase. Diabetes 57: 2626-2636, 2008.

7. Meier M, Menne $J$ and Haller $H$ : Targeting the protein kinase $C$ family in the diabetic kidney: lessons from analysis of mutant mice. Diabetologia 52: 765-775, 2009. 
8. Kanwar M and Kowluru RA: Role of glyceraldehyde 3-phosphate dehydrogenase in the development and progression of diabetic retinopathy. Diabetes 58: 227-234, 2009.

9. Ma RC, Tam CH, Wang Y, et al: Genetic variants of the protein kinase C-beta 1 gene and development of end-stage renal disease in patients with type 2 diabetes. JAMA 304: 881-889, 2010.

10. Gaudreault N, Perrin RM, Guo M, Clanton CP, Wu MH and Yuan SY: Counter regulatory effects of PKCbetaII and PKCdelta on coronary endothelial permeability. Arterioscler Thromb Vasc Biol 28: 1527-1533, 2008 .

11. Park JY, Takahara N, Gabriele A, et al: Induction of endothelin-1 expression by glucose: an effect of protein kinase $\mathrm{C}$ activation. Diabetes 49: 1239-1248, 2000

12. Geraldes P, Hiraoka-Yamamoto J, Matsumoto M, et al: Activation of PKC $\delta$ and SHP-1 by hyperglycemia causes vascular cell apoptosis and diabetic retinopathy. Nat Med 15: 1298-1307, 2009.

13. Khamaisi M, Dahan R, Hamed S, Abassi Z, Heyman SN and Raz I: Role of protein kinase $\mathrm{C}$ in the expression of endothelin converting enzyme-1. Endocrinology 150: 1440-1449, 2009.

14. Hayashida T and Schnaper HW: High ambient glucose enhances sensitivity to TGF-beta1 via extracellular signal-regulated kinase and protein kinase Cdelta activities in human mesangial cells J Am Soc Nephrol 15: 2032-2041, 2004.

15. Horovitz-Fried M, Brutman-Barazani T, Kesten D and Sampson SR: Insulin increases nuclear protein kinase Cdelta in L6 skeletal muscle cells. Endocrinology 149: 1718-1727, 2008.

16. Sud N, Wedgwood S and Black SM: Protein kinase Cdelta regulates endothelial nitric oxide synthase expression via Akt activation and nitric oxide generation. Am J Physiol Lung Cell Mol Physiol 294: L582-L591, 2008.

17. Hennige AM, Ranta F, Heinzelmann I, et al: Overexpression of kinase-negative protein kinase Cdelta in pancreatic betacells protects mice from diet-induced glucose intolerance and beta-cell dysfunction. Diabetes 59: 119-127, 2010.

18. Turck N, Richert S, Gendry P, et al: Proteomic analysis of nuclear proteins from proliferative and differentiated human colonic intestinal epithelial cells. Proteomics 4: 93-105, 2004.
19. Lim JH, Park JW, Kim SH, Choi YH, Choi KS and Kwon TK: Rottlerin induces pro-apoptotic endoplasmic reticulum stress through the protein kinase C-delta-independent pathway in human colon cancer cells. Apoptosis 13: 1378-1385, 2008.

20. Soltoff SP: Rottlerin: an inappropriate and ineffective inhibitor of PKCdelta. Trends Pharmacol Sci 28: 453-458, 2007.

21. Boini KM, Hennige AM, Huang DY, et al: Serum- and glucocorticoid-inducible kinase 1 mediates salt sensitivity of glucose tolerance. Diabetes 55: 2059-2066, 2006.

22. Hills CE, Squires PE and Bland R: Serum and glucocorticoid regulated kinase and disturbed renal sodium transport in diabetes. J Endocrinol 199: 343-349, 2008.

23. Kumar JM, Brooks DP, Olson BA and Laping NJ: Sgk, a putative serine/threonine kinase, is differentially expressed in the kidney of diabetic mice and humans. J Am Soc Nephrol 10: 2488-2494, 1999.

24. Brunet A, Park J, Tran H, Hu LS, Hemmings BA and Greenberg ME: Protein kinase SGK mediates survival signals by phosphorylating the forkhead transcription factor FKHRL1 (FOXO3a). Mol Cell Biol 21: 952-965, 2001.

25. Wolf G, Wenzel U, Ziyadeh FN and Stahl RA: Angiotensin converting-enzyme inhibitor treatment reduces glomerular p16INK4 and p27Kip1 expression in diabetic BBdp rats. Diabetologia 42: 1425-1432, 1999.

26. Sanghera DK, Ortega L, Han S, et al: Impact of nine common type 2 diabetes risk polymorphisms in Asian Indian Sikhs: PPARG2 (Pro12Ala), IGF2BP2, TCF7L2 and FTO variants confer a significant risk. BMC Med Genet 9: 59, 2008.

27. Liu W, Sun M, Jiang J, Shen X, Sun Q, Shen H and Gu J: Cyclin D3 interacts with human activating transcription factor 5 and potentiates its transcription activity. Biochem Biophys Res Commun 321: 954-960, 2004.

28. Choi SL, Choi YS, Kim YK, et al: Proteomic analysis and the antimetastatic effect of $\mathrm{N}$-(4-methyl)phenyl-O-(4-methoxy) phenyl-thionocarbamate-induced apoptosis in human melanoma SK-MEL-28 cells. Arch Pharm Res 29: 224-234, 2006. 